\title{
Effect of chronic Sildenafil treatment on the prostate of C57Bl/6 mice
}

\author{
Fabiana Oliveira dos Santos Gomes ${ }^{\mathrm{a}, \mathrm{b}, *}$, Maria da Conceição Carvalho ${ }^{\mathrm{c}}$, \\ Karina Lidianne Alcântara Saraiva ${ }^{\mathrm{d}}$, Edlene Lima Ribeiro ${ }^{\mathrm{a}, \mathrm{b}}$, \\ Amanda Karolina Soares e Silva ${ }^{\mathrm{a}, \mathrm{b}}$, Mariana Aragão Matos Donato ${ }^{\mathrm{a}, \mathrm{b}}$, \\ Sura Wanessa Santos Rocha ${ }^{a, b}$, Bruna Santos e Silva ${ }^{a, b}$, Christina Alves Peixoto ${ }^{a}$ \\ a Laboratório de Ultraestrutura do Instituto Aggeu Magalhães (FIOCRUZ), Brazil \\ ${ }^{\mathrm{b}}$ Universidade Federal de Pernambuco (UFPE), Brazil \\ ${ }^{\text {c }}$ Laboratório de Microscopia e Microanálise do Centro de Tecnologias Estratégicas do Nordeste (CETENE), Brazil

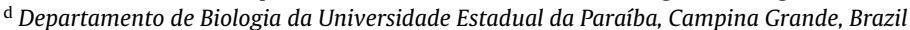

\section{A R T I C L E I N F O}

\section{Article history:}

Received 1 March 2014

Received in revised form 23 June 2014

Accepted 1 August 2014

Available online 11 August 2014

\section{Keywords:}

Sildenafil

Inhibitor of phosphodiesterase-5 (PDE5)

Prostate

\begin{abstract}
A B S T R A C T
Sildenafil is a potent and selective inhibitor of phosphodiesterase-5 (PDE5) and is considered firstline therapy for erectile dysfunction. Nowadays, Sildenafil is used extensively throughout the world on patients with pulmonary hypertension. However, few studies have evaluated the possible side effects of chronic Sildenafil treatment on the male reproductive system, specifically in the prostate. In the present study, it was demonstrated via morphological and ultrastructural analysis that chronic treatment with Sildenafil induced an enhancement of the glandular activity of the prostate. In addition, mice treated with Sildenafil showed a significant increase in testosterone serum levels. However, no statistically significant differences were observed in nitric oxide serum levels, or in SGC, eNOS, PSA and TGF- $\beta$ prostatic expression. In conclusion, the present study suggests that chronic use of Sildenafil does not cause evident prostatic damage, and therefore, can be used pharmacologically to treat a variety of disorders.
\end{abstract}

(C) 2014 Elsevier Ltd. All rights reserved.

\section{Introduction}

Inhibitor PDE-5, such as Sildenafil (Viagra), Vardenafil (Levitra), and Tadalafil (Cialis), has been used as a pharmacological vasodilator tool for several non-urological (pulmonary hypertension, systemic hypertension, diabetes, cardioprotection and endothelial function) and urological (erectile dysfunction, lower urinary tract symptoms, benign prostatic hyperplasia, priapism, premature ejaculation, and Peyronie's disease) disorders (Bella et al., 2007).

Phosphodiesterases (PDEs) are enzymes that are widely distributed in the body, hydrolyzing cyclic nucleotides, cAMP and cGMP to their inactive $5^{\prime}$-monofosfatos forms. Experimental studies using immunohistochemical methods have detected PDE isoenzymes 4, 5 and 11 in the fibromuscular prostatic stroma, as well as in the glandular structures of the transition zone of the prostate, suggesting that PDE enzymes play an important role in

\footnotetext{
* Corresponding author at: Instituto Aggeu Magalhães, FIOCRUZ, Av. Av. Professor Moraes, Rego, s/n - Campus da UFPE - Cidade Universitária, CEP: 50.670-420 Recife, Brazil. Tel.: +55 8121012557; fax: +55 8121012516 .

E-mail address: gomes.bio@gmail.com (F.O.d.S. Gomes).
}

dynamic activity, secretory function and prostatic tissue proliferation (Ückert et al., 2006a,b).

The PDE-5 enzyme is responsible for the hydrolysis of the GMPc, which restores GMP levels. Endothelial-derived nitric oxide (NO) activates soluble guanylyl cyclase (sGC) in vascular smooth muscle, leading to an increase in intracellular cGMP, which activates cytosolic cGMP-dependent protein kinase (PKG). The ability of Sildenafil to compete kinetically with PDE5 by the cGMP catalytic site makes it a select inhibitor of PDE5 (Francis and Corbin, 1999). The accumulation of cGMP induced by Sildenafil promotes relaxation of the smooth muscle cells, not only in the corpus cavernosum, but also in the bladder neck, urethra and prostate, by decreasing intracellular calcium concentration (Wang, 2010; Liu et al., 2007).

McVary et al. (2007) reported satisfactory results in a randomized, double blind, placebo-controlled study of 12-week, once-daily dosing of 50 and $100 \mathrm{mg}$ of Sildenafil in 369 men with ED and LUTS. Other authors also demonstrated a positive effect on urinary obstruction and irritation symptoms (Ying et al., 2004; Mulhall et al., 2006; Roehrborn et al., 2008; Stief et al., 2008).

Studies support the idea that PDE-5 expression increases in several types of human carcinoma, such as colon adenocarcinoma, bladder squamous carcinoma and lung cancers, suggesting the 

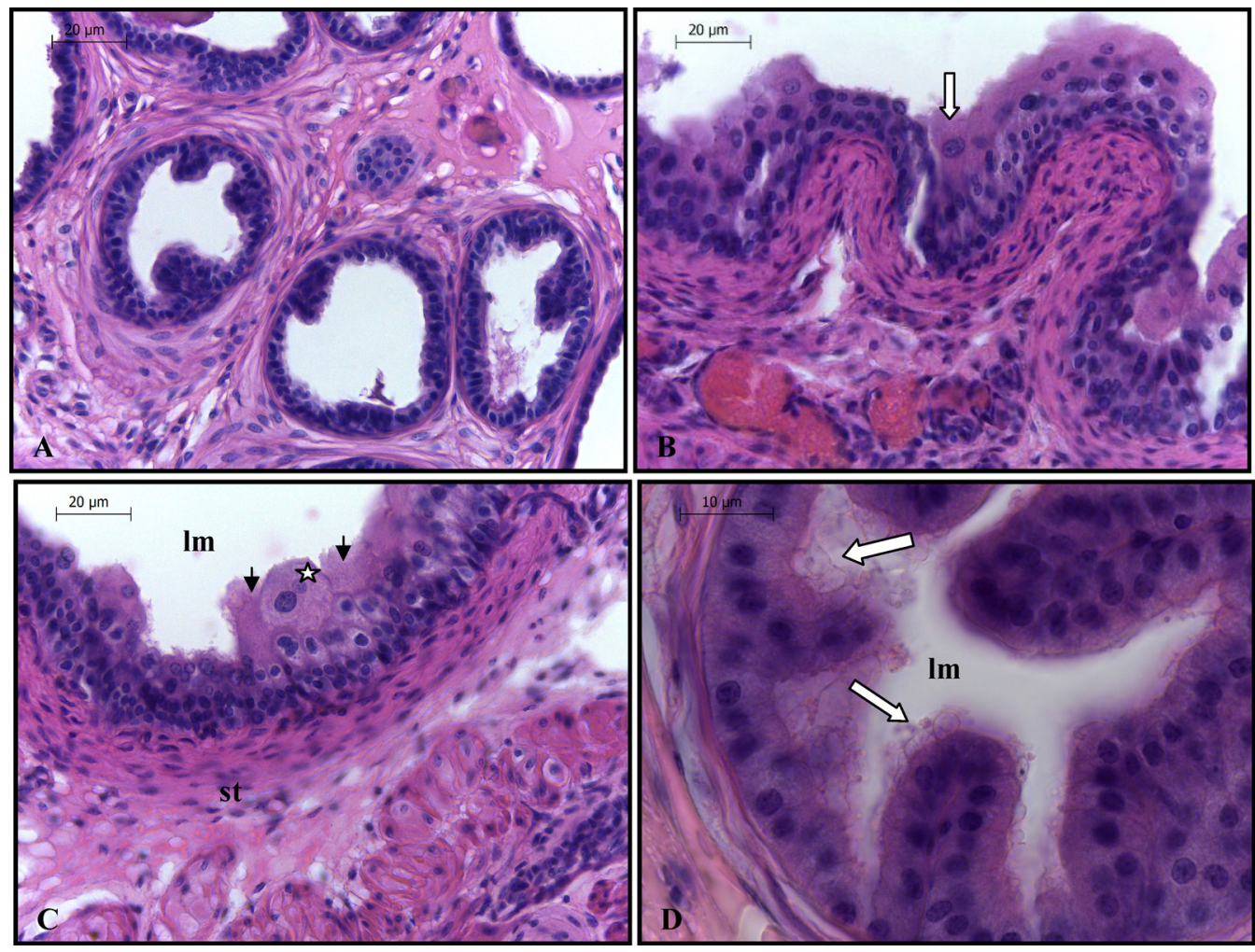

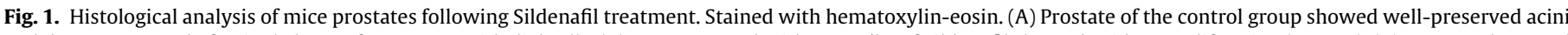

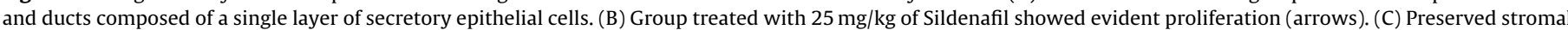

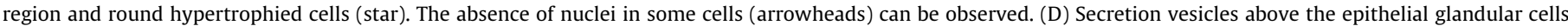
(arrows). (ep, epithelium; lm, lumen; st, stroma. $n=20$ mice from each group.

involvement of these enzymes in the control of cell proliferation and apoptotic mechanisms (Piazza et al., 2001; Moon et al., 2002; Whitehead et al., 2003; Sarfati et al., 2003). Additionally, in human prostate cancer cell lines, the increase of intracellular second messengers (cAMP and cGMP) initiates morphologic differentiation, inhibiting the growth and the invasive potential of these cells (Bang et al., 1994; Goto et al., 1999).

Studies have also demonstrated that Sildenafil attenuated pulmonary hypertension by increasing the supply of blood to the lungs reducing the right ventricular systolic pressure, right ventricular hypertrophy, the pulmonary artery muscularization, suggesting that the NO-cGMP pathway contributed to the drug response (Zhao et al., 2001, 2003).

Based on these evidences, in 2005, Sildenafil (Revatio, Pfizer) was approved for the chronic treatment of pulmonary hypertension. Recently, the Food and Drug Administration (FDA) and European Medical Agency (EMA) approved the daily use of the PDE5 inhibitor as a new opportunity for men with BPH/LUTS with coexisting ED.

Therefore, Sildenafil have a potential therapeutic indication for several chronic diseases; however the safety, efficacy and costeffectiveness need to be ascertained. There is a paucity of data on the long-term effects of chronic PDE-5 inhibitor use on the prostatic function. Since Sildenafil has a vasodilatation action as a result of its effect on $\mathrm{NO} / \mathrm{sGC} / \mathrm{GMPc} / \mathrm{PKG}$ pathways, the aim of the present study was to investigate the effect of chronic Sildenafil treatment on prostate model mice. The following end points were achieved: (1) prostate histopathology (histology and ultrastructure), (2) detection of sGC, PSA and TGF- $\beta$ (immunohistochemical), (3) nitric oxide (NO) synthesis (nitrite concentration), (4) expression of sGC, eNOS and TGF- $\beta$ (western blot), and (5) hormonal assays (testosterone dosage).

\section{Materials and methods}

\subsection{Animals}

Forty pubertal male C57BL/6 mice (obtained from the Centro de Pesquisas Aggeu Magalhães/FIOCRUZ, Recife, Brazil) aged 25 days and weighing 15-20g were used in all experiments. Mice were examined for health status and acclimated to the laboratory environment, which had a temperature of $23^{\circ} \mathrm{C}$ and a $12 \mathrm{~h}$ light: $12 \mathrm{~h}$ dark photoperiod. The animals were housed in metal cages and fed a standard diet and water ad libitum. The experimental group was composed of 11 animals, which received a dose of $25 \mathrm{mg} / \mathrm{kg}$ body weight of Sildenafil (Pfizer Inc., New York, NY, USA) for 4 weeks, administered through drinking water (Zhao et al., 2003). Body weight was recorded every day and the drug concentration in the water was adjusted to maintain the dose. The control group was also composed of 20 animals, which received only pure water, using the same procedure as described above. All experiments were performed according to ethical guidelines (L-0035/08 - CEUA/FIOCRUZ). After treatment with Sildenafil, the experimental and control animals were anaesthetized with ketamine $(115 \mathrm{mg} / \mathrm{kg}, \mathrm{i} . \mathrm{m}$.) and xylazine $(10 \mathrm{mg} / \mathrm{kg}$, i.m.) (Sespo Comércio e Indústria Ltda., Sao Paulo, Brazil), before blood collection by cardiac puncture without anticoagulant. The serum was separated and stored at $-70^{\circ} \mathrm{C}$ for testosterone hormone radioimmunoassay. The prostates were quickly dissected and fixed for morphological analysis.

\subsection{Light microscopy}

The prostates were fixed in Bouin's solution for $8 \mathrm{~h}$. Next, they were dehydrated in an ethanol series and embedded in paraffin 

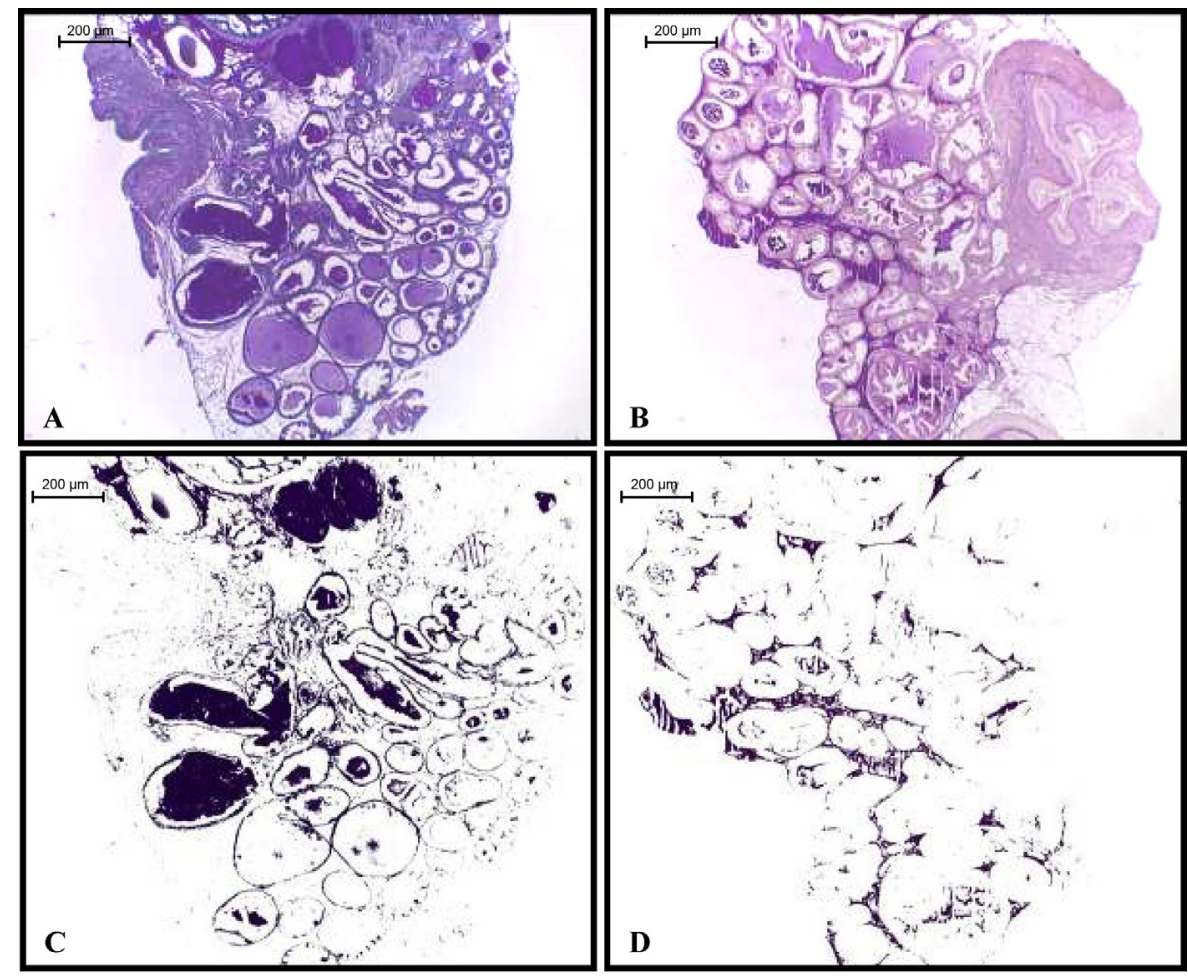

$\mathbf{E}$

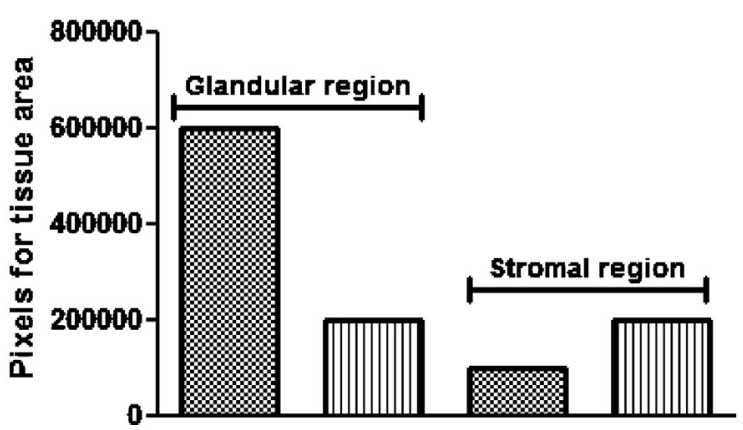

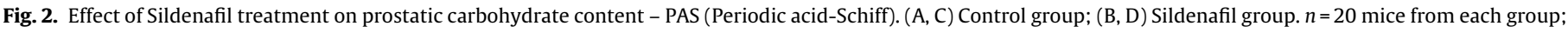
(E) quantification of tissue area in pixels.

wax. Serial sections of $5 \mu \mathrm{m}$ were cut using a microtome (Leica RM 2125RT), stained with hematoxylin-eosin and PAS (periodic acid-Schiff), and evaluated with an inverted microscopy (Observer $\mathrm{Z1}$, Zeiss Micro Imaging $\mathrm{GmbH}$ ) equipped with a camera and 4.7.4 image analysis program (AxionCam MRm Zeiss) at a magnification of $400 \times$.

\subsection{Electron transmission microscopy}

The fragments of prostate were fixed overnight in a solution containing $2.5 \%$ glutaraldehyde and $4 \%$ paraformaldehyde in $0.1 \mathrm{M}$ cacodylate buffer. After fixation, the samples were washed twice in the same buffer and were then post-fixed in a solution containing $1 \%$ osmium tetroxide, $2 \mathrm{mM}$ calcium chloride and $0.8 \%$ potassium ferricyanide in $0.1 \mathrm{M}$ cacodylate buffer, $\mathrm{pH} 7.2$, dehydrated in acetone, and embedded in Embed 812. Polymerization was performed at $60{ }^{\circ} \mathrm{C}$ for 3 days. Ultrathin sections were collected on 300-mesh nickel grids, counterstained with $5 \%$ uranyl acetate and lead citrate, and examined using a FEI Morgani 268D transmission electron microscope.

\subsection{Immunohistochemical assays for sGC, PSA and TGF- $\beta$}

Ultrathin sections ( $5 \mu \mathrm{m}$ in thickness) of each group were cut and adhered to slides treated with 3-amino-propyl-trietoxi-silane (APES [Sigma, USA]). Briefly, sections were deparaffinized with xylene and rehydrated in graded ethanol (100-70\%). The sections were heated for $30 \mathrm{~min}$ in a sodium citrate buffer $(0.01 \mathrm{M}, \mathrm{pH} 6.0)$ to increase epitope exposure. To minimize endogenous peroxidase activity, the slides were treated with $0.3 \%(\mathrm{v} / \mathrm{v}) \mathrm{H}_{2} \mathrm{O}_{2}$ in water for $5 \mathrm{~min}$. The sections were washed with $0.01 \mathrm{M}$ PBS (pH 7.2) and then blocked with $1 \%$ BSA, $0.2 \%$ Tween 20 in PBS for $1 \mathrm{~h}$, at room temperature. The sections were then incubated for $12 \mathrm{~h}$ at $4{ }^{\circ} \mathrm{C}$ with rabbit polyclonal antibody against anti-guanylyl cyclase $\beta 1$ soluble (sGC) (Sigma, USA), polyclonal antibody prostate-specific antigen (PSA) (ABCAM, CA, USA), and rabbit polyclonal transforming growth factor $\beta$ s (TGF- $\beta$ ) (Santa Cruz Biotechnology, Santa Cruz, CA). The optimal concentration used for these antibodies was $1: 100$. The antigen-antibody reaction was visualized with avidinbiotin peroxidase (Dako Universal $\mathrm{LSAB}^{\circledR}+$ Kit, Peroxidase) using 3.3-diaminobenzidine as the chromogen. The slides were counterstained in hematoxylin. Positive staining resulted in a brown 

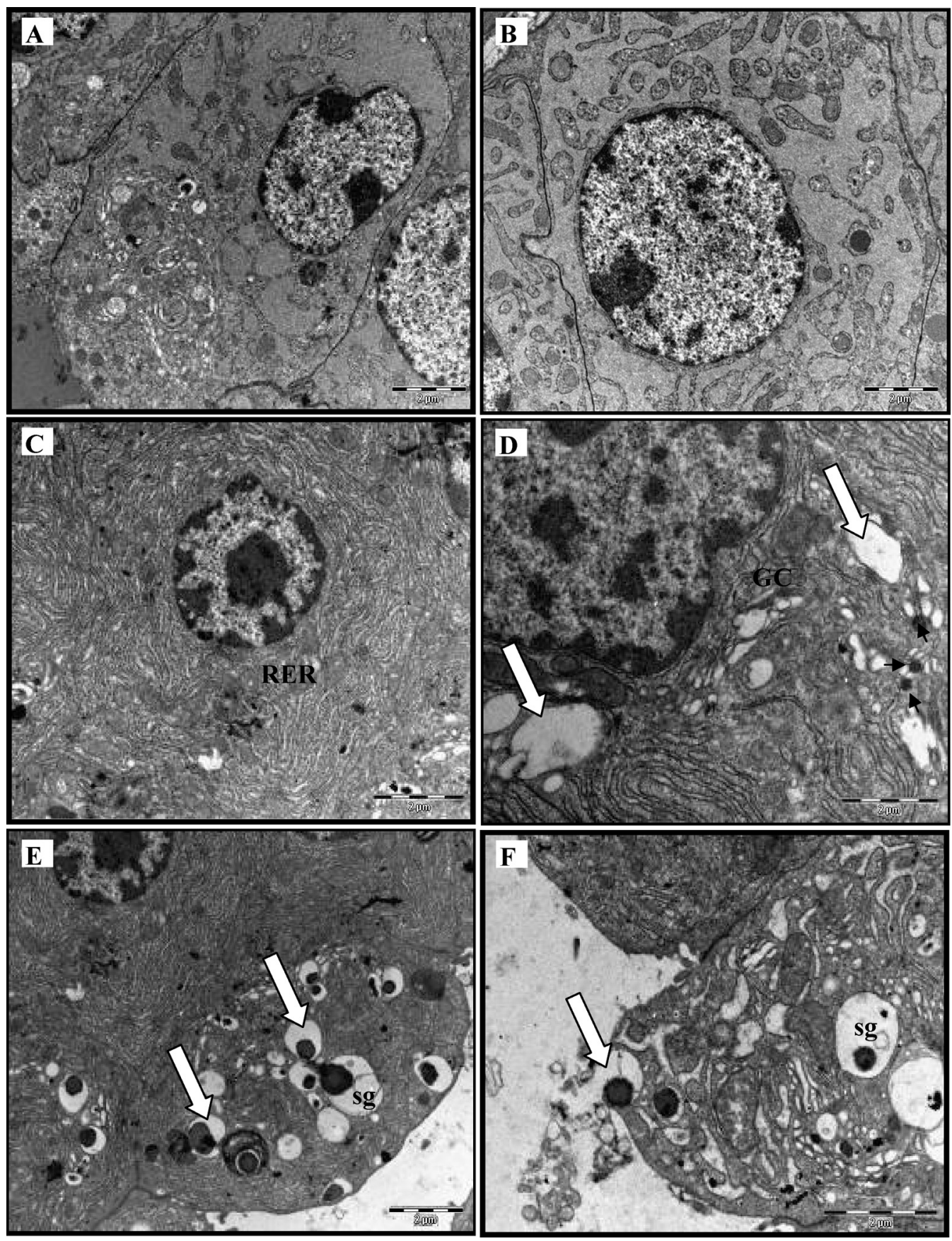

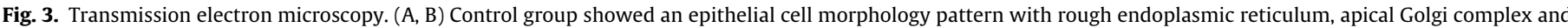

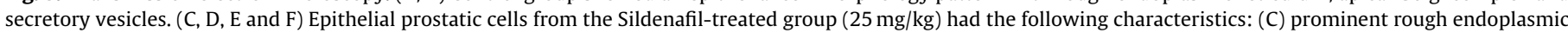

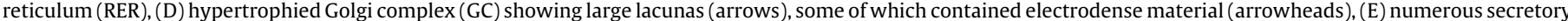
granules were observed in the apical region ( $\mathrm{sg}$ ) with electrodense material (arrows), and (F) exocitosis (arrow).

reaction product. Negative controls were treated as above, but with the omission of the first antibody. Five pictures taken at the same magnification were quantitatively analyzed using Gimp 2.6 software (GNU Image Manipulation Program, UNIX platforms).

\subsection{Hormone assays}

Serum testosterone was assayed using a solid-phase radioimmunoassay kit in accordance with the manufacturer's instructions (Coat-A-Count Total Testosterone; Diagnostic Products Corporation, Los Angeles, CA, USA). The sensitivity of the testosterone assay was $4 \mathrm{ng} / \mathrm{dl}$ and the intra- and inter-assay variation coefficients were $4-18 \%$ and $5.9-12 \%$, respectively. The values were expressed in $\mathrm{ng} / \mathrm{ml}$. Data were analyzed using the Mann-Whitney test to compare testosterone levels of the controls and the organisms that underwent Sildenafil treatment (Zar, 1996).

\subsection{Measurement of NO}

Greiss colorimetric reaction, which detects nitrite $\left(\mathrm{NO}_{2}{ }^{-}\right)$and oxidation of $\mathrm{NO}$ in serum, was used to measure nitric oxide. Blood was obtained by cardiac puncture and centrifuged at $1000 \times g$ for $10 \mathrm{~min}$. Subsequently serum samples were diluted fourfold with distilled water, and deproteinized by adding $1 / 20$ th volume of 

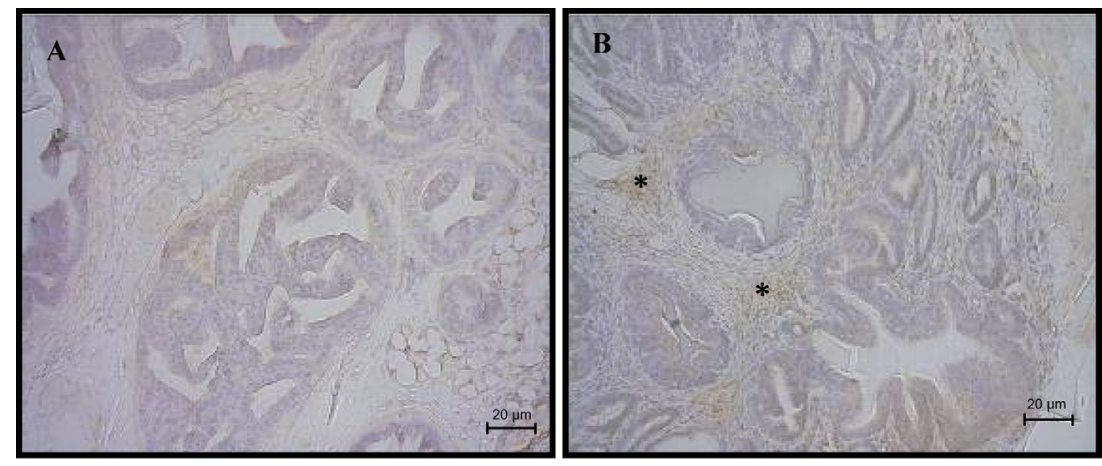

C
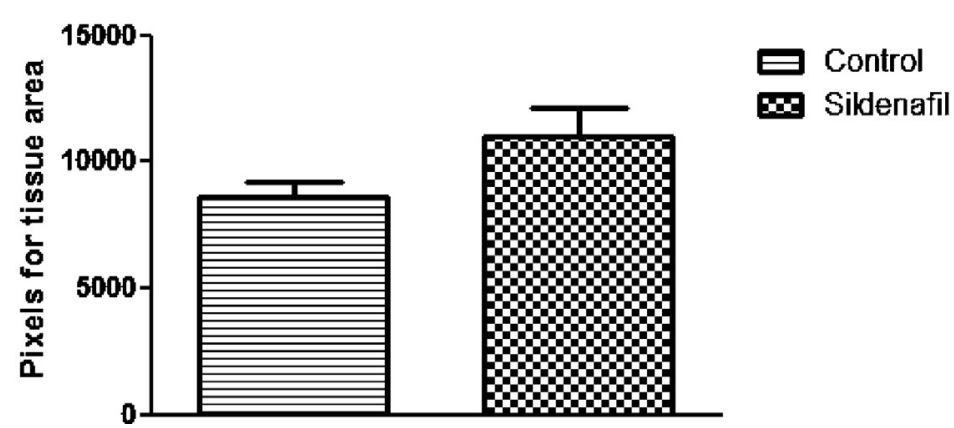

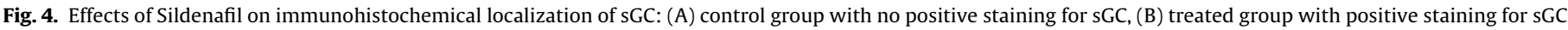
when Sildenafil was administered for 30 days, and $(C)$ pixel quantification of tissue area. $n=10$ mice from each group.

a zinc sulfate solution $(300 \mathrm{~g} / \mathrm{L})$, to give a final concentration of $15 \mathrm{~g} / \mathrm{L}$. After $3500 \times \mathrm{g}$ centrifugation for $10 \mathrm{~min}, 100 \mu \mathrm{L}$ of samples were added to an ELISA plate (96 wells) in duplicate, followed by the same volume of Griess reagent. Griess reagent is composed of $1 \%$ sulfanilamide diluted in $2.5 \% \mathrm{H}_{3} \mathrm{PO}_{4}$ (solution $\mathrm{A}$ ) and $\mathrm{N}-1$ naphtyl-ethtylenodiamina, also diluted in $2.5 \% \mathrm{H}_{3} \mathrm{PO}_{4}$ (solution $\mathrm{B}$ ). To prepare a standard curve, a solution of sodium nitrite in an initial concentration of $100 \mu \mathrm{M}$ was serially diluted in PBS. After incubation for 10 min in the dark, a spectrophotometer reading was taken at $490 \mathrm{~nm}$. The absorbance of different samples was compared with the standard curve, and the results expressed as mean \pm standard error of the duplicate, using GraphPad Prism software (v. 5.0).

\subsection{Western blot for eNOS, sGC and TGF $\beta$}

The prostates were quickly dissected and then homogenized in a Wheaton Overhead Stirrer $\left(n^{\circ}\right.$ 903475) in an extraction cocktail $(10 \mathrm{mM}$ ethylenediamine tetraacetic acid (EDTA), $2 \mathrm{mM}$ phenylmethylsulfonyl fluoride (PMSF), $100 \mathrm{mM}$ sodium fluoride, $10 \mathrm{mM}$ sodium pyrophosphate, $10 \mathrm{mM}$ sodium orthovanadate $\left(\mathrm{NaVO}_{4}\right), 10 \mathrm{mg}$ of aprotinin and $100 \mathrm{mM}$ tris(hydroxymethyl)aminomethane, $\mathrm{pH}$ 7.4). Homogenates were centrifuged at $3000 \times g$ for $10 \mathrm{~min}$ and the supernatant was collected and stored at $-70^{\circ} \mathrm{C}$ until used for immunoblotting. Protein levels were determined using the Bradford method taking bovine serum albumin as standard (Bradford, 1970). The proteins ( $40 \mathrm{mg}$ ) were separated in $10 \%$ (sGC, eNOS and TGF- $\beta$ ) sodium dodecyl sulfate-polyacrylamide by gel electrophoresis under reduced conditions and were electrophoretically transferred onto nitrocellulose membrane (Bio Rad, CA, USA, Ref. 162-0115). After blocking overnight at $4{ }^{\circ} \mathrm{C}$ with $5 \%$ non-fat milk in TBS-T (Trisbuffered saline $0.1 \%$ plus $0.05 \%$ Tween $20, \mathrm{pH} 7.4$ ), the membranes were incubated at room temperature for $3 \mathrm{~h}$, with rabbit polyclonal antibody against eNOS (1:1000 dilution; BD Transduction Laboratories, USA), sGC (1:200 dilution, Abcam, CA, USA) and
TGF- $\beta$ (1:1000 dilution; Santa Cruz Biotechnology, Santa Cruz, CA), and diluted in buffer solution TBS-T containing 3\% non-fat milk. After washing (six times, $10 \mathrm{~min}$ each) in TBS-T, the membranes were further reacted with horseradish peroxidase-conjugated anti-rabbit secondary antibody (1:80,000 (Ref. A6154), diluted in TBS-T with $1 \%$ nonfat milk for $1 \mathrm{~h} 30 \mathrm{~min}$ at room temperature. An enhanced chemiluminescence reagent (Super Signal, Pierce, Ref. 34080) was used to make the labeled protein bands visible and the blots were developed on X-ray film (Fuji Medical, Kodak, Ref. Z358487-50EA). For quantification, the density of pixels of each band was determined using the Image J 1.38 program (available at http://rsbweb.nih.gov/ij/download.html; developed by Wayne Rasband, NIH, Bethesda, MD). For each protein investigated, the results were confirmed using three sets of experiments. Immunoblot for $\beta$-actin was used as a control for the protein blots. After protein blot visualization with enhanced chemiluminescence, the protein antibodies were stripped from the membranes, which were reprobed with monoclonal anti- $\beta$-actin antibody (1:2000 dilution, Sigma, USA), and protein densitometry was performed.

\subsection{Statistical analysis}

GraphPad Prism software, version 5 was used for statistical analysis. Data were expressed as mean \pm standard deviation. The differences between the control and treated groups were analyzed used Mann-Whitney or T-test. Probability values less than 0.05 were considered significant.

\section{Results}

\subsection{Morphological analysis}

Histological analysis of the prostate glands of animals in the control group showed well-preserved acini and ducts composed 

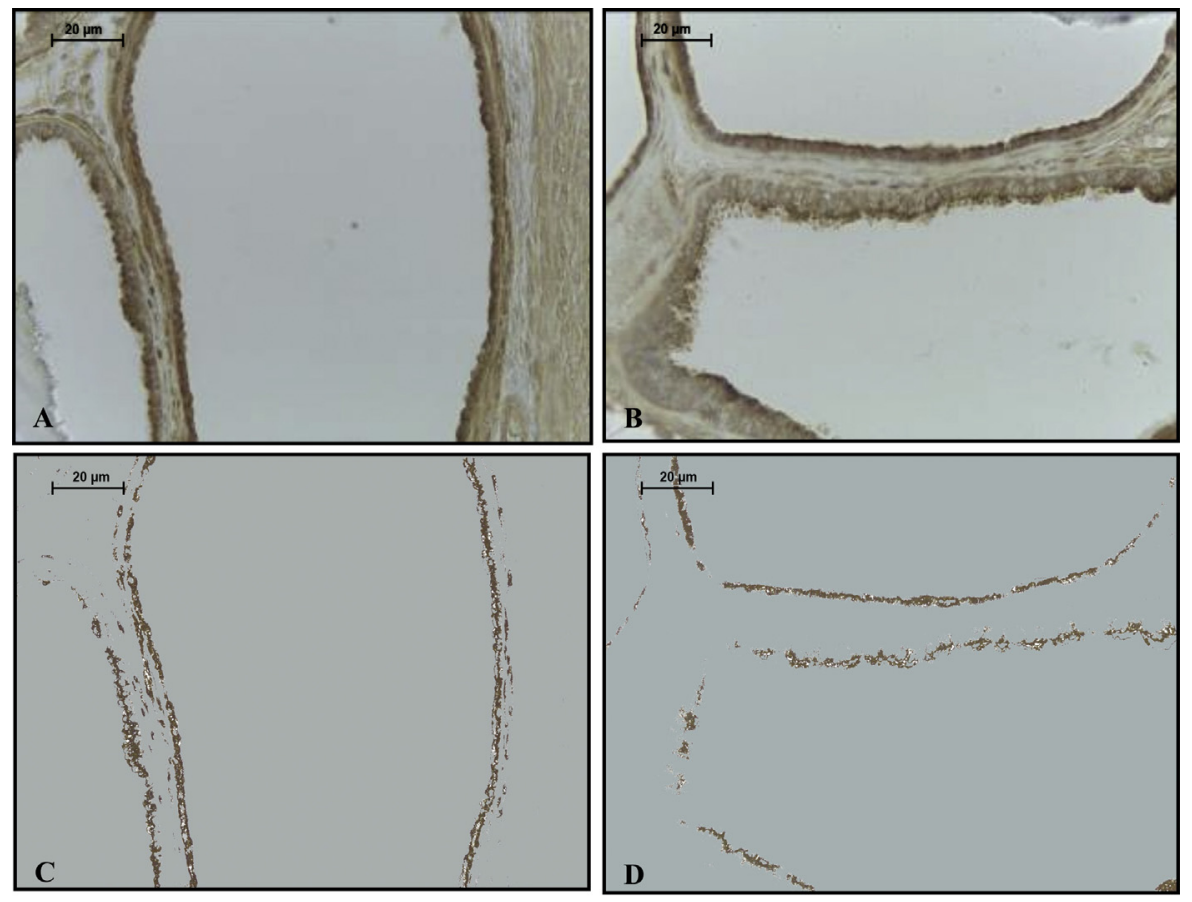

$\mathbf{E}$
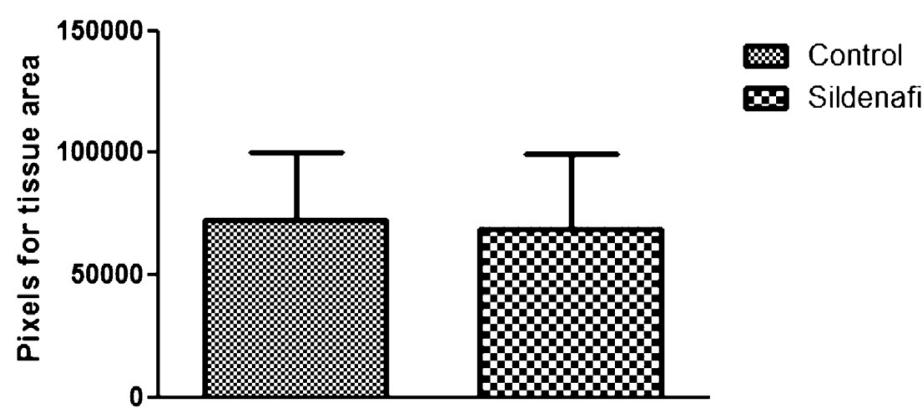

$\infty$ Sildenafil

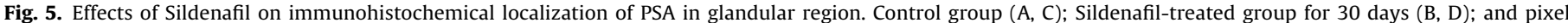
quantification (E). $n=10$ mice from each group.

of a single layer of secretory epithelial cells, characterized by columnar cells. Below the epithelium, there was a continuous layer of basal cells and a basal membrane. The stromal compartment, formed by a subepithelial region and a layer of smooth muscle cells surrounding the tubules, was also observed (Fig. 1A).

After 30 days of treatment with $25 \mathrm{mg} / \mathrm{kg}$ of Sildenafil, there was a clear difference between the Sildenafil treated and the control groups in the glandular and stromal regions. The secretory epithelium lining showed tall columnar cells in evident cellular proliferation (Fig. 1B), some of which were hypertrophied, with round profile and evident nuclei, while others had an absence of nuclei (Fig. 1C). Moreover, the glandular apical region showed evident secretion vesicles, indicating an increase in glandular activity (Fig. 1D).

\subsection{Carbohydrates}

The distribution of carbohydrates was analyzed using the Periodic acid-Schiff technique. In the control group, the presence of carbohydrates was identified in the glandular region (Fig. 2A). Contrastingly, there was increased labeling in the stromal region in the group treated with Sildenafil (Fig. 2B).

\subsection{Ultrastructural analysis}

Ultrastructural analysis of the prostate gland showed a columnar epithelium morphological pattern with evident elliptical nuclei, with rough endoplasmic reticulum (RER), apical Golgi complex and secretory vesicles (Fig. 3A and B). There were a small number of secretion vesicles with electron-lucent content with spherical eletrodense condensations.

Contrastingly, ultrastructural analysis of prostatic cells from the group treated with Sildenafil showed several characteristics of cellular activation, such as hypertrophied rough endoplasmic reticulum (Fig. 3C), dilated cistern of Golgi complex occupying the apical cellular region (Fig. 3D), containing electrodense secretion and numerous secretory vesicles (Fig. 3E). Exocytocis of the granular content was also observed (Fig. 3F).

\subsection{Immunohistochemical analysis for $s G C, P A S$ and TGF- $\beta$}

In the present study sGC expression in the prostate tissue was evaluated by immunohistochemical detection. Tissue sections obtained from mice from the control group demonstrated no positive staining for $\mathrm{SGC}$ in the stromal and glandular region (Fig. 4A). Slight staining for sGC was found in the stromal region 


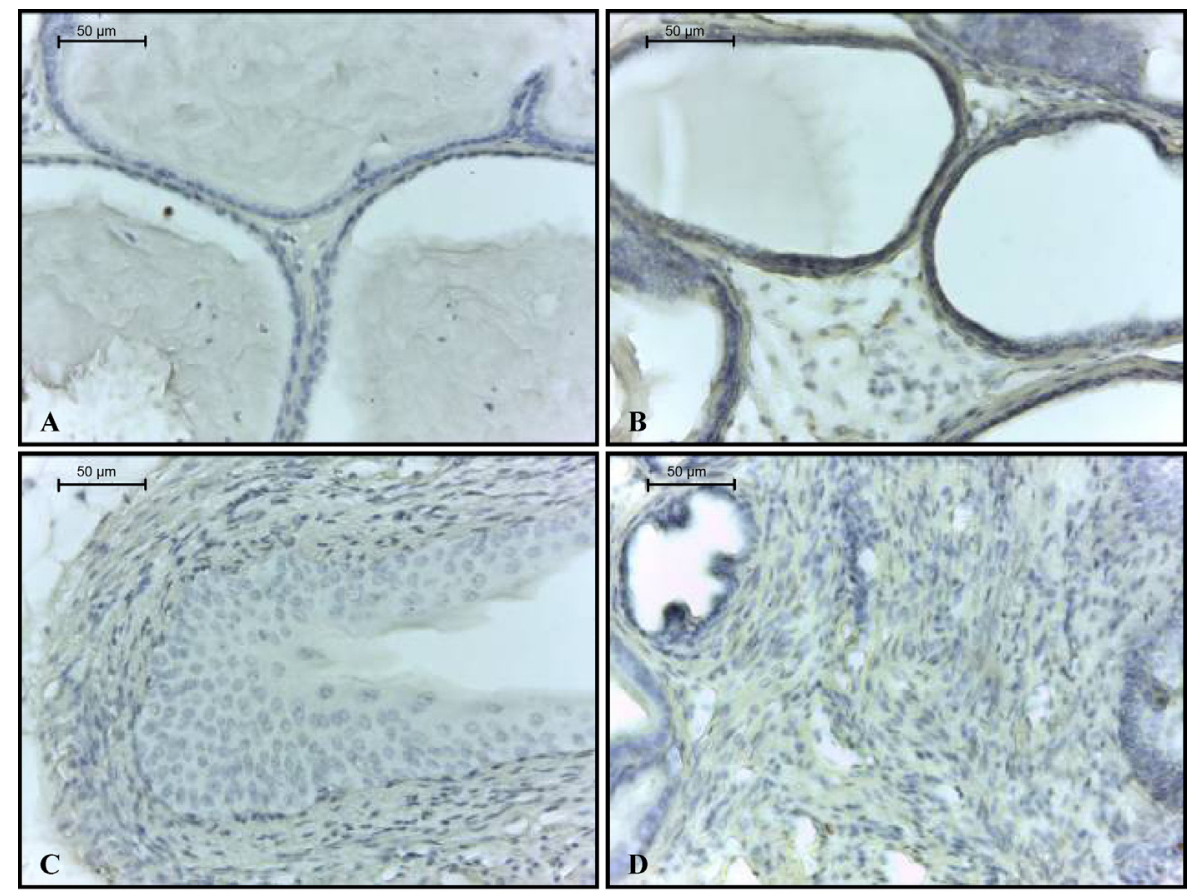

$\mathbf{E}$

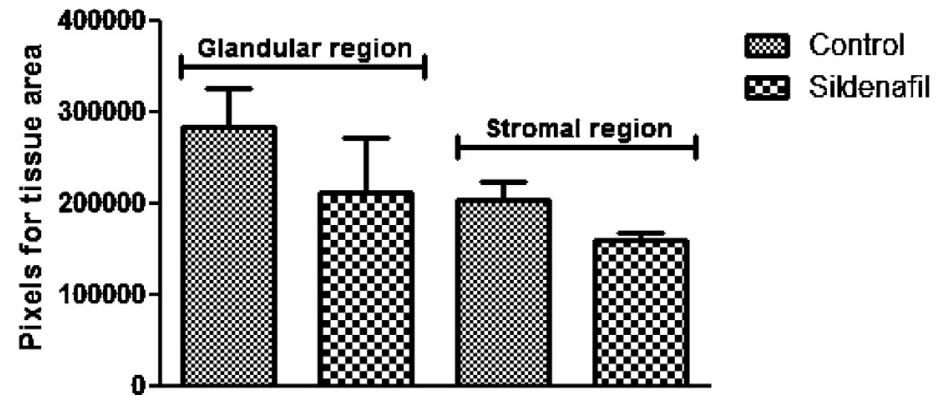

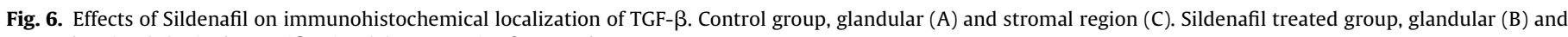
stromal region (D). Pixel quantification (E). $n=10$ mice from each group.

of the prostate of mice treated with Sildenafil $25 \mathrm{mg} / \mathrm{kg}$. However, pixel quantification did not indicate statistically significant difference (Fig. 4B and C).

Similarly, prostate tissue sections from the control and Sildenafil treated groups showed no significant differences for PSA (Fig. 5A-E) and TGF- $\beta$ (Fig. 6A-D) in the stromal and glandular regions.

\subsection{Hormone assay}

Serum testosterone levels were significantly higher in $25 \mathrm{mg} / \mathrm{kg}$ Sildenafil administered mice when compared with animals from the control group (Mann-Whitney, $P=0.0057$ ). The parameters of the two groups are shown in Table 1.

\subsection{Measurement of $\mathrm{NO}$}

NO levels in serum were analyzed using the Greiss reaction test. NO level was slightly higher in the Sildenafil $25 \mathrm{mg} / \mathrm{kg}$ group than in the control group, however the difference was not significant (Fig. 7).

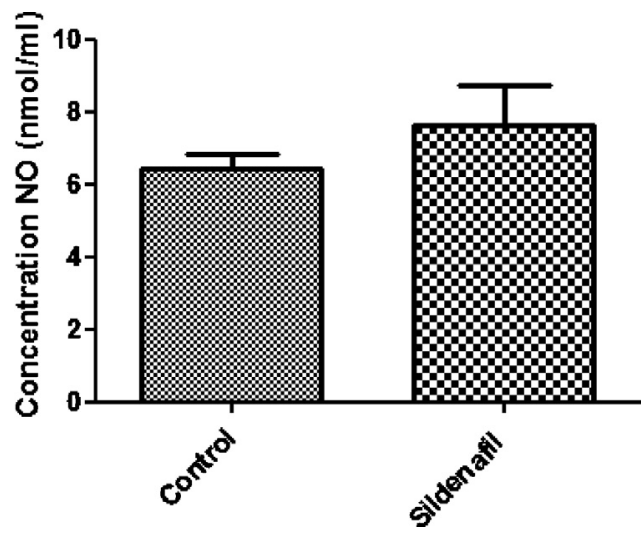

Fig. 7. Effect of Sildenafil on NO production in serum. Nitrite and nitrate levels and quantity of stable NO metabolites were higher in serum after treatment for 30 days, however the difference was not significant.

\subsection{Expression of eNOS, sGC and TGF $\beta$}

The expression of eNOS, SGC and TGF $\beta$ in prostate was analyzed using the Western blot technique. Chronic Sildenafil treatment did 
Table 1

Effect of Sildenafil treatment on mice serum testosterone levels ( $\mathrm{ng} / \mathrm{ml}$ ).

\begin{tabular}{|c|c|c|c|c|c|c|}
\hline & \multicolumn{6}{|c|}{ Serum testosterone levels $(\mathrm{ng} / \mathrm{ml})$} \\
\hline & $N$ & Mean & Minimum & Maximum & SD & Mann-Whitney \\
\hline Control & 11 & 0.74 & 0.19 & 2.4 & 0.70 & 18 \\
\hline Sildenafil $25 \mathrm{mg} / \mathrm{kg}$ & 11 & 5.74 & 0.41 & 11 & 4.71 & \\
\hline
\end{tabular}

Significant difference between Sildenafil $25 \mathrm{mg} / \mathrm{kg}$ and control samples, $P=0.0057$.

not result in a significant difference in SGC, eNOS and TGF $\beta$ expression (Fig. 8).

\section{Discussion}

Sildenafil has been used as a pharmacological strategy in the treatment of several urological and non-urogical disorders.
However, there are few detailed studies of the possible effects of chronic treatment with Sildenafil on the male reproductive system.

Saraiva et al. (2009) undertook an in vivo investigation of the effects of chronic Sildenafil treatment $(25 \mathrm{mg} / \mathrm{kg})$ on male Swiss Webster mice. This study demonstrated that Leydig cells had alterations in the smooth endoplasmic reticulum, large vacuoles scattered through the cytoplasm, enlarged mitochondria and cells with intense secretory activity and hormonal production. Other
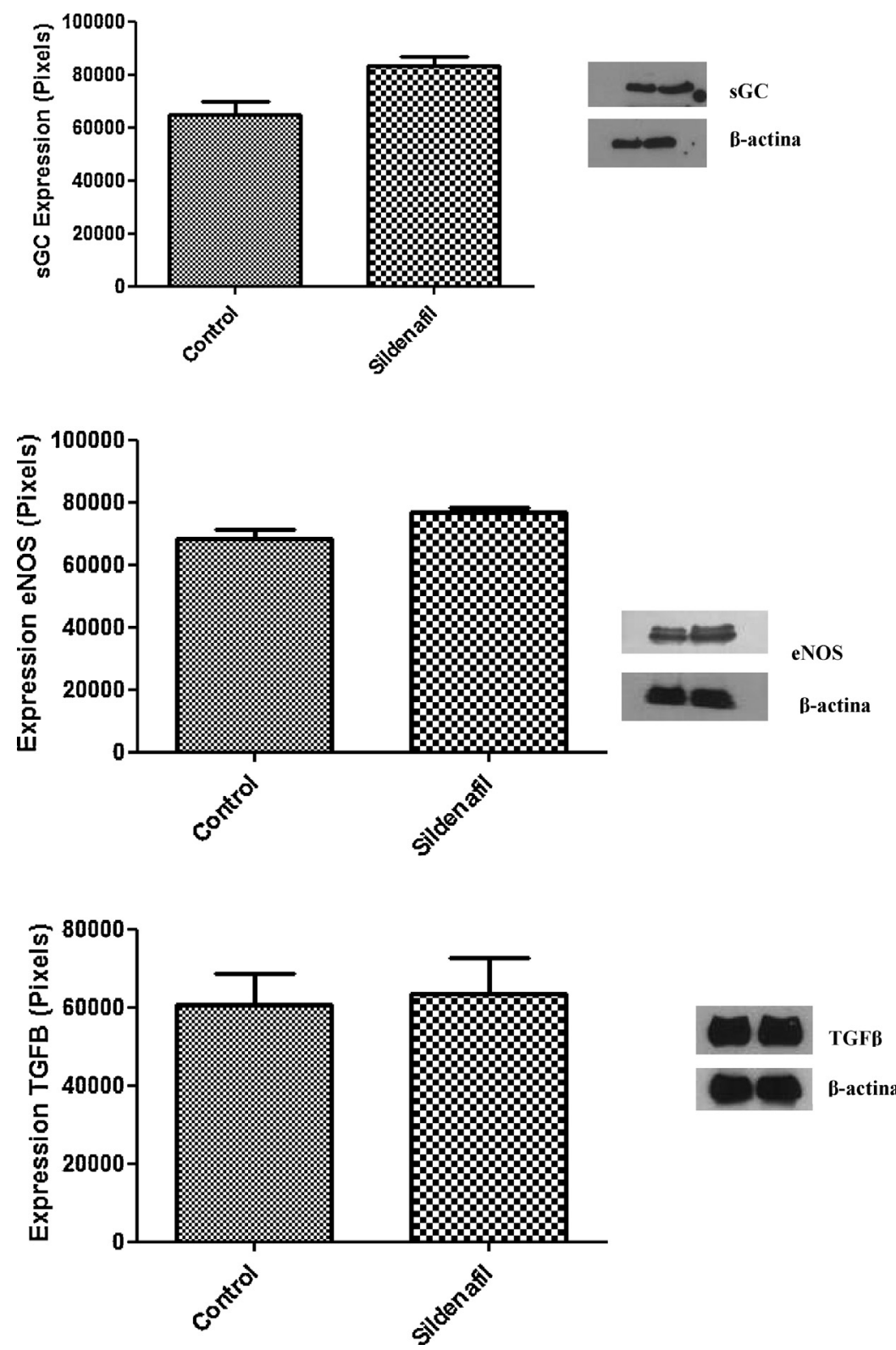

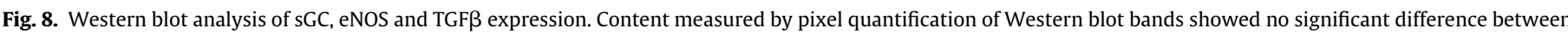
Sildenafil and control groups. 
in vitro studies found evidence of the antiproliferative effect of PDE inhibitors in smooth muscle cells from human BPH tissue (Wong et al., 2009; Adolfsson et al., 2002; Cook and Haynes, 2004).

The prostatic gland is composed of epithelial and stromal cells. Interactions of these cells with androgens have a fundamental role in the growth, development and differentiation of the prostate (Chung and Davies, 1996; Thomson et al., 2002; Hayward et al., 1997; Cunha et al., 2004).

In the present study, the effects of chronic treatment with Sildenafil on the prostrate of $\mathrm{C} 57 \mathrm{Bl} / 6$ mice were evaluated. Histological analysis showed no pathological alteration of the glandular and stromal region. However, epithelial cells showed some morphological characteristics of exacerbated activity. This hypothesis was confirmed by ultrastructural analysis as hypertrophied RER, prominent Golgi complex and secretory vesicle formation were identified. Histological glycogen staining using the periodic acid-Schiff (PAS) technique also confirmed that chronic treatment with Sildenafil induced prostatic secretion enhancement.

Differentiated prostatic epithelial cells can directly influence fibroblasts, vascular endothelial and inflammatory cells, to generate a microenvironment favorable to the onset of carcinogenesis (Cano et al., 2007).

The secretory function of the prostate is dependent upon direct stimulation of the prostatic epithelial cells by androgens (Hayward and Cunha, 2000). The importance of the interaction between steroid hormones and prostatic function has been studied in several prostatic pathologies in recent years. Androgen deprivation leads to loss of secretory function and a reduction in glandular size. This regression is caused by widespread apoptosis in the prostate (Kerr et al., 1972). Oliver et al. (2010) showed that in lower concentrations of testosterone the cyclic adenosine monophosphate (cAMP) is more active in human cultured prostatic stromal cells (HCPSC). Many authors have showed the association between testosterone serum levels and the risk of prostate cancer, while others have demonstrated opposing results (Hoffman et al., 2000; Gill et al., 2010).

Prostate-specific antigen (PSA) is a glycoprotein produced by the prostatic epithelial cells that is considered the most useful marker of prostate cancer (Bok and Small, 2002; Vermassen et al., 2012). Its regulation has important clinical implications on cleavage semenogelins and fibronectin in coagulated semen, causing liquefaction, and aiding fertilization (Lilja et al., 1987). The present study showed that chronic treatment with Sildenafil can stimulate prostatic activity possible by elevating testosterone levels. According to data from literature, testosterone can directly influence PSA levels; however, the results of the present study showed that although high testosterone serum levels were detected after chronic Sildenafil treatment, no significant expression of PSA was observed.

Several studies indicate that PSA can accelerate carcinogenesis in the prostate. PSA can directly affect proteolysis components of the basement membrane, which can aide tumor-cell invasion and metastasis (Webber et al., 1995). In the case of advanced prostate cancer, a decrease in PSA level after systemic therapy has been shown to correlate with an improved outcome (Small et al., 2001).

PSA is thought to cleave insulin-like growth-factor-binding protein 3 (IGFBP3), thereby liberating insulin-like growth-factor 1 (IGF1), which is a mitogen to the prostatic stromal and epithelial (Cohen et al., 1992; Sutkowski et al., 1999; Djavan et al., 2001). PSA can also activate latent transforming growth factor (TGF)- $\beta$, which can stimulate cell detachment and facilitate the spread of tumor-cells (Killian et al., 1993). Based on these observations, the expression of TGF prostatic tissue was evaluated by western blot. No significant difference was detected after Sildenafil treatment, which is consistent with PSA results.
Metabolic syndrome (MetS) is a complex of clustering metabolic abnormalities and comprises a number of disorders such as insulin resistance, hypertension and obesity, which all act as risk factors for cardiovascular diseases. Recent studies have demonstrated that MetS, BPH/LUTS and prostatic cancer are often comorbid (Hammarsten and Peeker, 2011). Hyperinsulinemia, hyperglycemia and insulin-like growth factor-1 (IGF-1) contribute to the development and progression of BPH/LUTS. Hyperinsulinemia is also associated with increased sympathetic nervous system activity via enhanced glucose metabolism. This process promotes the increase in $\alpha$-adrenergic receptors leading to increased smooth muscle tone of the male genitourinary tract (McVary, 2006; Ozden et al., 2007). The is a clear association between autonomic neural input and prostate growth rate (McVary et al., 1994). Besides, fasting plasma insulin, in particular, has been linked to BPH and lethal prostate cancer (Hammarsten and Peeker, 2011).

Another association between insulin resistance and $\mathrm{BPH}$ is related to IGF-1. Since these molecules have similar structure, insulin can bind to IGF-1 receptors and activate the signaling pathway for growth and proliferation of epithelial and stromal prostatic cells (Nunzio et al., 2012).

Chronic inflammation is one of the putative links between MetS and BPH/LUTS. Recently, Vignozzi et al. (2013) demonstrated that PDE5 blockade exerts anti-inflammatory effects on myofibroblast prostatic cells, blunting inflammatory and metabolic insults. These authors showed that treatment with tadalafil or vardenafil suppressed IL-8 and IP-10 secretion induced by inflammatory (TNF- $\alpha$ ) and metabolic (oxLDL, AGE and IGF-1) stimuli, also suppressing TNF- $\alpha$ genes related to inflammation or tissue remodeling.

Other studies suggest that PDE5i could be a pharmacological strategy for the treatment of ED and LUTS/BPH by modifying NO/cGMP signaling pathway and improving the RhoA/Rho-kinase (ROCK), besides reducing the hyperactivity of the autonomic nervous system and chronic pelvic ischemia (Gacci et al., 2013).

Nitric oxide is a gas that is synthesized intracellularly by three NOS isoforms: neuronal (nNOS), inducible (iNOS), and endothelial (eNOS) (Andersson, 2007; Aaltomaa et al., 2000; Uotila et al., 2001; Cronauer et al., 2007; Nanni et al., 2009; Sanli et al., 2011; Yu et al., 2013). It has been demonstrated that the isoform eNOS plays a predominant role in tumor growth, metastasis and angiogenesis in human prostate cancer (PC), as well as in maintenance of the vascular tone and mediating vascular endothelial growth factor (VEGF)-induced endothelial cell activation (Ying and Hofseth, 2007; Polytarchou et al., 2009; Ziaei et al., 2013).

The fibromuscular stroma is densely supplied by NO synthasecontaining nerve terminals (Burnett et al., 1995). According to the data from literature, the NO plays an important role in the control of prostate function in mammals and humans, including the regulation of prostate smooth muscle tone, glandular secretory function and local blood flow (Hedlund, 2005; Andersson, 2007; Kedia et al., 2008).

Activators of the NO/GMPc signaling cascade may interfere with regulation of smooth stromal muscle tone (Waldkirch et al., 2007). Secondary messengers, cyclic adenosine monophosphate (cAMP) and cyclic guanosine monophosphate (cGMP) are synthesized by activation of adenylyl-and guanylyl-cyclases, respectively, and degraded by cyclic nucleotide phosphodiesterases (PDE) (Hall, 1993). Nitric oxide (NO) activates soluble guanylyl cyclase (sGC), leading to an increase in intracellular cGMP, which activates cytosolic cGMP-dependent protein kinase (PKG). Soluble guanylyl cyclase ( $\mathrm{sGC}$ ) is considered the most important receptor for the signaling molecule NO (Carvajal et al., 2000; Ückert et al., 2006a,b).

To evaluate if chronic Sildenafil treatment could influence the NO/cGMP cascade in prostate, levels of serum NO, immunohistochemistry for sGC and western blot for sGC and eNOS were 
evaluated. No statistical significant differences were observed in nitric oxide serum level or in SGC and eNOS prostatic expression.

\section{Conclusion}

In summary, chronic treatment with Sildenafil $(25 \mathrm{mg} / \mathrm{kg})$ induced an enhancement of prostatic glandular activity, possibly due to increased testosterone production. However, there was no increase in the expression of PSA and TGF- $\beta$. This data suggest that extensive use of Sildenafil in non-urological disorders such as pulmonary hypertension may not damage the prostate.

\section{Conflicts of interest}

The authors declare that there is no conflict of interest regarding the publication of this article.

\section{Acknowledgments}

This study was supported by Fundação Oswaldo Cruz (FIOCRUZ) and Fundação de Amparo à Ciência e Tecnologia de Pernambuco (FACEPE).

\section{References}

Aaltomaa, S.H., Lipponen, P.K., Viitanen, J., et al., 2000. The prognostic value of inducible nitric oxide synthase in local prostate cancer. BJU Int. 86, 234-239.

Adolfsson, P.I., Ahlstrand, C., Varenhorst, E., Svensson, S.P., 2002. Lysophosphatidic acid stimulates proliferation of cultured smooth muscle cells from human BPH tissue: sildenafil and papaverin generate inhibition. Prostate 51, 50-58.

Andersson, K.E., 2007. LUTS treatment: future treatment options. Neurourol. Urodyn. 26, 928-933.

Bang, Y.J., Pirnia, F., Fang, W.G., et al., 1994. Terminal neuroendocrine differentiation of human prostate carcinoma cells in response to increased intracellular cyclic AMP. Proc. Natl. Acad. Sci. U. S. A. 91, 5330-5334.

Bella, A.J., Deyoung, L.X., Al-Numi, M., Brock, G.B., 2007. Daily administration of phosphodiesterase Type 5 inhibitors for urological and nonurological indications. Eur. Urol. 52, 990-1005.

Bok, R.A., Small, E.J., 2002. Bloodborne biomolecular markers in prostate cancer development and progression. Nat. Rev. Cancer 2, 918-926.

Burnett, A.L., Maguire, M.P., Chamness, S.L., et al., 1995. Characterization and localization of nitric oxide synthase in the human prostate. Urology 45, 435-439.

Cano, P., Godoy, A., Escamilla, R., et al., 2007. Stromal-epithelial cell interactions and androgen receptor-coregulator recruitment is altered in the tissue microenvironment of prostate cancer. Cancer Res. 67, 511-519.

Carvajal, J.A., Germain, A.M., Huidobro-Toro, J.P., Weiner, C.P., 2000. Molecular mechanism of cGMP-mediated smooth muscle relaxation. J. Cell. Physiol. 184, 409-420.

Chung, L.W., Davies, R., 1996. Prostate epithelial differentiation is dictated by its surrounding stroma. Mol. Biol. Rep. 23, 13-19.

Cohen, P., Graves, H.C., Peehl, D.M., et al., 1992. Prostate-specific antigen (PSA) is an insulinlike growth factor binding protein-3 protease found in seminal plasma. J. Clin. Endocrinol. Metab. 75, 1046-1053.

Cook, A.L., Haynes, J.M., 2004. Protein kinase G II-mediated proliferative effects in human cultured prostatic stromal cells. Cell Signal. 16, 253-261.

Cronauer, M.V., Ince, Y., Engers, R., et al., 2007. Nitric oxide-mediated inhibition of androgen receptor activity: possible implications for prostate cancer progression. Oncogene 26, 1875-1884.

Cunha, G.R., Ricke, W., Thomson, A., et al., 2004. Hormonal, cellular, and molecular regulation of normal and neoplastic prostatic development. J. Steroid Biochem. Mol. Biol. 92, 221-236.

De Nunzio, C., Aronson, W., Freedland, S.J., et al., 2012. The correlation between metabolic syndrome and prostatic diseases. Eur. Urol. 61, 560-570.

Djavan, B., Waldert, M., Seitz, C., Marberger, M., 2001. Insulin-like growth factors and prostate cancer. World J. Urol. 19, 225-233.

Francis, S.H., Corbin, J.D., 1999. Cyclic nucleotide-dependent protein kinases: intracellular receptors for cAMP and cGMP action. Crit. Rev. Clin. Lab. Sci. 36, 275-328.

Gill, J.K., Wilkens, L.R., Pollak, M.N., 2010. Androgens, growth factors, and risk of prostate cancer: the Multiethnic Cohort. Prostate 70, 906-915.

Goto, T., Matsushima, H., Kasuya, Y., et al., 1999. The effect of papaverine on morphologic differentiation, proliferation and invasive potential of human prostatic cancer LNCaP cells. Int. J. Urol. 6, 314-319.

Gacci, M., Sebastianelli, A., Salvi, M., et al., 2013. PDE5-Is for the treatment of concomitant ED and LUTS/BPH. Curr. Bladder Dysfunct. Rep. 8, 150-159.

Hall, I.P., 1993. Isoenzyme selective phosphodiesterase inhibitors: potential clinical uses. Br. J. Clin. Pharmacol. 35, 1-7.

Hammarsten, J., Peeker, R., 2011. Urological aspects of the metabolic syndrome. Nat. Rev. Urol. 8, 483-494.
Hayward, S.W., Cunha, G.R., 2000. The prostate: development and physiology. Radiol Clin. North Am. 38, 1-14.

Hayward, S.W., Rosen, M.A., Cunha, G.R., 1997. Stromal-epithelial interactions in the normal and neoplastic prostate. Br. J. Urol. 79, 18-26.

Hedlund, P., 2005. Nitric oxide/CGMP-mediated effects in the out-flow region of the lower urinary tract - is there a basis for pharmacological targeting of cGMP? World J. Urol. 23, 362-367.

Hoffman, M.A., DeWolf, W.C., Morgentaler, A., 2000. Is low serum free testosterone a marker for high grade prostate cancer? J. Urol. 163, 824-827.

Kedia, G.T., Uckert, S., Jonas, U., 2008. The nitric oxide pathway in the human prostate: clinical implications in men with lower urinary tract symptoms. World J. Urol. 26, 603-609

Kerr, J.F., Wyllie, A.H., Currie, A.R., 1972. Apoptosis: a basic biological phenomenon with wide-ranging implications in tissue kinetics. Br. J. Cancer 26, 239-257.

Killian, C.S., Corral, D.A., Kawinski, E., Constantine, R.I., 1993. Mitogenic response of osteoblast cells to prostate-specific antigen suggests an activation of latent TGF$\beta$ and a proteolytic modulation of cell adhesion receptors. Biochem. Biophys. Res. Commun. 192, 940-947.

Lilja, H., Oldbring, J., Rannevik, G., Laurell, C.B., 1987. Seminal vesicle-secreted proteins and their reactions during gelation and liquefaction of human semen. J. Clin. Invest. 80, 281-285.

Liu, C.M., Lo, Y.C., Wu, B.N., et al., 2007. cGMP-enhancing- and $\alpha 1 \mathrm{~A} / \alpha 1 \mathrm{D}-$ adrenoceptor blockade-derived inhibition of Rho-kinase by KMUP-1 provides optimal prostate relaxation and epithelial cell anti-proliferation efficacy. Prostate 67, 1397-1410.

McVary, K.T., Monnig, W., Camps Jr., J.L., et al., 2007. Sildenafil citrate improves erectile function and urinary symptoms in men with erectile dysfunction and lower urinary tract symptoms associated with benign prostatic hyperplasia: a randomized, double-blind trial. J. Urol. 177, 1071-1077.

McVary, K.T., 2006. Lower urinary tract symptoms and sexual dysfunction: epidemiology and pathophysiology. BJU Int. 97, 23-28.

McVary, K.T., Razzaq, A., Lee, C., et al., 1994. Growth of the rat prostate gland is facilitated by the autonomic nervous system. Biol. Reprod. 51, 99-107.

Moon, E., Lee, R., Near, R., et al., 2002. Inhibition of PDE3B augments PDE4 inhibitorinduced apoptosis in a subset of patients with chronic lymphocytic leukemia. Clin. Cancer Res. 8, 589-595.

Mulhall, J.P., Guhring, P., Parker, M., Hopps, C., 2006. Assessment of the impact of sildenafil citrate on lower urinary tract symptoms in men with erectile dysfunction. J. Sex. Med. 3, 662-667.

Nanni, S., Benvenuti, V., Grasselli, A., et al., 2009. Endothelial NOS, estrogen receptor beta, and HIFs cooperate in the activation of a prognostic transcriptional pattern in aggressive human prostate cancer. J. Clin. Invest. 119, 1093-1108.

Oliver, V.L., Anderson, C., Ventura, S., Haynes, J.M., 2010. Androgens regulate adenylate cyclase activity and intracellular calcium in stromal cells derived from human prostate. Prostate 70, 1222-1232.

Ozden, C., Ozdal, O.L., Urgancioglu, G., et al., 2007. The correlation between metabolic syndrome and prostatic growth in patients with benign prostatic hyperplasia. Eur. Urol. 51, 199-203.

Piazza, G.A., Thompson, W.J., Pamukcu, R., et al., 2001. Exisulind, a novel proapoptotic drug, inhibits rat urinary bladder tumorigenesis. Cancer Res. 61, 3961-3968.

Polytarchou, C., Hatziapostolou, M., Poimenidi, E., et al., 2009. Nitric oxide stimulates migration of human endothelial and prostate cancer cells through up-regulation of pleiotrophin expression and its receptor protein tyrosine phosphatase beta/zeta. Int. J. Cancer 124, 1785-1793.

Roehrborn, C.G., McVary, K.T., Elion-Mboussa, A., Viktrup, L., 2008. Tadalafil administered once daily for lower urinary tract symptoms secondary to benign prostatic hyperplasia: a dose finding study. J. Urol. 180, 1228-1234.

Sanli, O., Kucukgergin, C., Gokpinar, M., et al., 2011. Despite the lack of association between different genotypes and the presence of prostate cancer, endothelial nitric oxide synthase a/b (eNOS4a/b) polymorphism may be associated with advanced clinical stage and bone metastasis. Urol. Oncol. 29, 183-188.

Saraiva, K.L., Silva, A.K., Wanderley, M.I., et al., 2009. Chronic treatment with sildenafil stimulates Leydig cell and testosterone secretion. Int. J. Exp. Pathol. 90 454-462.

Sarfati, M., Mateo, V., Baudet, S., et al., 2003. Sildenafil and vardenafil, types 5 and 6 phosphodiesterase inhibitors, induce caspase-dependent apoptosis of B-chronic lymphocytic leukemia cells. Blood 101, 265-269.

Small, E.J., McMillan, A., Meyer, M., et al., 2001. Serum prostate-specific antigen decline as a marker of clinical outcome in hormone-refractory prostate cancer patients: association with progression-free survival, pain end points, and survival. J. Clin. Oncol. 19, 1304-1311.

Stief, C.G., Porst, H., Neuser, D., et al., 2008. A randomised, placebo-controlled study to assess the efficacy of twice-daily vardenafil in the treatment of lower urinary tract symptoms secondary to benign prostatic hyperplasia. Eur. Urol. 53, $1236-1244$

Sutkowski, D.M., Goode, R.L., Baniel, J., et al., 1999. Growth regulation of prostatic stromal cells by prostate-specific antigen. J. Natl. Cancer Inst. 91, 1663-1669.

Thomson, A.A., Timms, B.G., Barton, L., et al., 2002. The role of smooth muscle in regulating prostatic induction. Development 129 (8), 1905-1912.

Ückert, S., Hedlund, P., Andersson, K.E., et al., 2006a. Update on phosphodiesterase (PDE) isoenzymes as pharmacological targets in urology: present and future. Eur. Urol. 50, 1194-1207.

Ückert, S., Oelke, M., Stief, C.G., et al., 2006b. Immunohistochemical distribution of cAMP- and CGMP-phosphodiesterase (PDE) isoenzymes in the human prostate. Eur. Urol. 49, 740-745. 
Uotila, P., Valve, E., Martikainen, P., et al., 2001. Increased expression of cyclooxygenase-2 and nitric oxide synthase-2 inhuman prostate cancer. Urol. Res. 29, 23-28.

Vermassen, T., Speeckaert, M.M., Lumen, N., et al., 2012. Glycosylation of prostate specific antigen and its potential diagnostic applications. Clin. Chim. Acta 413, 1500-1505.

Vignozzi, L., Gacci, M., Cellai, I., et al., 2013. PDE5 inhibitors blunt inflammation in human BPH: a potential mechanism of action for PDE5 inhibitors in LUTS. Prostate 73, 1391-1402.

Waldkirch, E.S., Uckert, S., Langnäse, K., et al., 2007. Immunohistochemical distribution of cyclic GMP-dependent protein kinase-1 in human prostate tissue. Eur. Urol. 52, 495-501.

Wang, C., 2010. Phosphodiesterase-5 inhibitors and benign prostatic hyperplasia. Curr. Opin. Urol. 20, 49-54.

Webber, M.M., Waghray, A., Bello, D., 1995. Prostate-specific antigen, a serine protease, facilitates human prostate cancer cell invasion. Clin. Cancer Res. 1, 1089-1094.

Whitehead, C.M., et al., 2003. Exisulind-induced apoptosis in a non-small cell lung cancer orthotopic lung tumor model augments docetaxel treatment and contributes to increased survival. Mol. Cancer Ther. 2, 479-488.
Wong, P., Lawrentschuk, N., Bolton, D.M., 2009. Phosphodiesterase 5 inhibitors in the management of benign prostatic hyperplasia and erectile dysfunction: the best of both worlds. Curr. Opin. Urol. 19, 7-12.

Ying, J., Yao, D., Jiang, Y., et al., 2004. The positive effect of sildenafil on LUTS from BPH while treating ED. Zhonghua Nan Ke Xue 10, 681-683.

Ying, L., Hofseth, L.J., 2007. An emerging role for endothelial nitric oxide synthase in chronic inflammation and cancer. Cancer Res. 67, 1407-1410.

Yu, S., Jia, L., Zhang, Y., et al., 2013. Increased expression of activated endothelial nitric oxide synthase contributes to antiandrogen resistance in prostate cancer cells by suppressing androgen receptor transactivation. Cancer Lett. 328 83-94.

Zar, J.H., 1996. Biostatistical Analysis, third ed. Prentice-Hall, Upper Saddle River, NJ, $662 \mathrm{pp}$.

Zhao, L., Mason, N.A.,Strange, J.W., Walker, H., Wilkings, M.R., 2003. Beneficial effects of phosphodiesterase 5 inhibition in pulmonary hypertension are influenced by natriuretic peptide activity. Circulation 107, 234-237.

Zhao, L., Mason, N.A., Morell, N.W., et al., 2001. Sildenafil inhibits hypoxia pulmonary hypertension. Circulation 104, 424-428.

Ziaei, S.A., Samzadeh, M., Jamaldini, S.H., et al., 2013. Endothelial nitric oxide synthase Glu298Asp polymorphism as a risk factor for prostate cancer. Int. J. Biol. Markers 28, 43-48. 